\title{
HIV Infection among 50 Years and above Attending HIV Counseling and Testing (HCT) in Nnewi, Nigeria
}

\author{
0. Kalu Stephen ${ }^{1 *}$, Ofiaeli Ngozi1 ${ }^{1}$ U. Ele Prince1, Reynolds Fiona ${ }^{2}$, O. Oluboyo Bernard1, \\ 0. Chukwuma George ${ }^{3}$, A. Nwabueze Simeon ${ }^{4}$, E. Anyabolu Arther ${ }^{5}$, 0. Igwegbe Anthony ${ }^{6}$ \\ ${ }^{1}$ HIV care Department, Nnamdi Azikiwe University Teaching Hospital, Nnewi, Nigeria \\ ${ }^{2}$ Peoples Open Access Initiative, Manchester, UK \\ ${ }^{3}$ Medical Laboratory Science Department, Nnamdi Azikiwe University, Nnewi, Nigeria \\ ${ }^{4}$ Community Medicine Department, Nnamdi Azikiwe University/Teaching Hospital, Nnewi, Nigeria \\ ${ }^{5}$ Medicine Department, Nnamdi Azikiwe University Teaching Hospital, Nnewi, Nigeria \\ ${ }^{6}$ Obsteritrics and Gynecology Department, Nnamdi Azikiwe University Teaching Hospital, Nnewi, Nigeria \\ Email: "chiefokorafor@yahoo.com,gozzyobi@yahoo.co.uk, princeele2005@yahoo.com, \\ fionaynolds@gmail.com, pelumibenboyo@yahoo.com, georgechuma@yahoo.com, \\ achunnam05@yahoo.com, ebeleanyabolu@yahoo.com, tigwegbe@yahoo.com
}

Received 25 January 2014; revised 25 February 2014; accepted 4 March 2014

Copyright (C) 2014 by authors and Scientific Research Publishing Inc.

This work is licensed under the Creative Commons Attribution International License (CC BY).

http://creativecommons.org/licenses/by/4.0/

(c) $\underset{\mathrm{EY}}{0}$ Open Access

\section{Abstract}

Background: Human Immunodeficiency Virus (HIV)/Acquired Immune Deficiency Syndrome (AIDS) has afflicted persons of all ages leading to increase spread of the virus. This study attempts to determine the prevalence of HIV infection among 50 years of age and above over the five years of study in Nnewi, Nigeria. Methods: Males and females who were 50 years and above who underwent HCT in Nnewi between January 2008 to November 2012 were counseled and tested for HIV antibodies after giving an oral consent. Results: Of the 57,090 clients offered HCT, 4384 (7.7\%) were 50 years and above while 52,706 (92.3\%) were 15 - 49 years of age. The crude HIV prevalence was $8.2 \%$. HIV infection in the 50 - 59 years of age was 2.4 times higher than that in the 60 years of age and above. A higher prevalence was observed in females $(8.8 \%)$ compared with $7.8 \%$ in males in our study. No female $\mathbf{7 5}$ years and over was found to have HIV infection in our study $(0 \%)$ while males in the same age group had a prevalence of $3.0 \%$. The prevalence in our study was higher compared to the 2010 ANC sentinel survey (8.7\%) in Anambra state. Conclusion: Our findings show that offering HCT routinely is feasible and may increase linkage to HIV care and treatment for many individuals with HIV infections. Routine HCT should be an integral component of any expansion in HIV prevention, care and treatment services in Africa and other settings where the prevalence of HIV is high. House to house HIV testing will improve uptake of testing among

${ }^{*}$ Corresponding author. 


\section{older population in developing countries.}

\section{Keywords}

\section{HIV Infection; HCT}

\section{Background}

Traditionally, older people have been held in high esteem in many African societies for their wisdom, role as heads of families and in conflict resolution. Some authors have used the term "gerontocracy" to illustrate the powerful position older people hold in most African societies [1] [2]. Both counseling and testing are key components of HIV prevention and care programmes [3]. Through HIV counseling and testing (HCT), uninfected individuals can take steps to avoid becoming infected, while infected individuals can avoid transmission to sexual partners or children [4]. Moreover, HCT is the first step in referral to care and support services [5]. HIV among 50 years and above has been largely ignored in sub-Saharan Africa (SSA) [6], though a recent study estimated that there are three million HIV positive people in SSA aged 50 and above representing more than 14\% of those over the age of 15 infected [7]. Despite this, most HIV prevention efforts focus largely on 15 - 49 years of age and little is known about HIV among 50 years and above. Individuals $>49$ years of age account for approximately $10 \%$ of the cumulative HIV infection case-load in the United States of America [8]; the corresponding proportions for Nigeria and Africa are not known. This study therefore seeks:

1) To measure the prevalence of HIV infection in age group 50 years and above in Nnewi, Nigeria.

2) To compare the prevalence in those 50 years and above with 15 - 49 years of age.

3) To estimate the HIV incidence in this age group to determine whether HIV infection was acquired only among younger ages or also in older adults.

4) To compare the 2010 HCT extrapolated data results for both males and females aged 15 - 49 years with the 2010 ANC sentinel survey for Anambra state, Nigeria.

\section{Methodology}

\subsection{Design}

The study was a prospective cohort of middle aged (50 - 59 years) and geriatric population (60 years and above) who underwent HIV Counseling and Testing (HCT) in Nnewi, Nigeria.

\subsection{Setting}

The study was conducted at the HCT unit of the Institute of Human Virology of the Nnamdi Azikiwe University Teaching Hospital, Nnewi between January 2008 and November 2012.

\subsection{Inclusion Criteria}

1) Clients 50 years and above in age who also gave oral informed consent.

2) "Out" patients and in' patients 50 years and above whose clinicians requested for their retroviral tests.

3) The 15 - 49 years population was extrapolated from the HCT data.

\subsection{Exclusion Criteria}

1) Clients who were referred from other hospitals and laboratories.

2) Patients who were on antiretroviral (ARV) drugs.

3) HIV positive patients who came to HCT to check if they have been cured after taking some concoctions.

\section{Methods}

The trained nursing counselors in HCT unit gave clients group pre-test counseling-this involved education on 
HIV, modes of transmission, risk factors, and the methods of prevention and a brief talk on what HIV rapid test is. The counselor sought for clients' oral informed consent before their blood specimen was collected by the nurse phlebotomists. Those that gave an oral consent were recruited into the study. The participants were interviewed to obtain information on demography and risk sexual behaviours. The data clerk gave each participant a unique identifier (not the client's name) that eventually links information with the client's test result. 5ml of blood was collected into an EDTA vacutainer bottle and separated; the resulting plasma was tested for antibodies to HIV. The HIV testing was performed in a two-step serial algorithm. Determine HIV-1/2 assay (Abbott Laboratories, Illinois, and United States of America) was used for the screening of all the specimens, the HIV1/2 STAT-PAK Dipstick assay (Chembio Diagnostic Systems Inc., New York, USA) was used for the confirmation of all samples that tested positive with Determine test kits while the Uni-Gold test (Trinity Biotech, Wicklow, Ireland) was used as the tie-breaker. An HIV-negative result with the Determine assay was reported as negative. An HIV-positive result with the Determine assay was confirmed using the STAT-PAK assay and was reported as positive if both tests gave positive results. If the Determine and STAT-PAK assay results were discordant, the sample was subjected to a third test kit, (the Uni-Gold) to resolve all discordant results. The result was reported as positive if the Uni-Gold test result was positive and negative if both STAT-PAK assay and UniGold test results were negative. The nurse counselors called in the participants one on one for the post test counseling in other to maintain confidentiality while giving the rapid test result to the participants. Results were given the same day to the participants by the counselors. All participants, whether HIV-negative or HIV-positive, were counseled on risk reduction during the post test counseling. For clients who tested positive to HIV antibodies, counselors provided emotional support, encouraged and discussed risk and harm reduction as well as safe sex practices, gave clients information on the HIV/AIDS care available, partner counseling and referrals to HIV/AIDS clinics for follow-up care. Clients were also offered partner counseling and referrals services at this time. For clients who tested negative, counselors discussed the client's risk reduction plan and the importance of window period and subsequent retesting. The data on HIV testing for clients who were 15 - 49 years of age were extrapolated from the HCT records to be able to compare uptake of HCT with 50 years of age and above population/prevalence of the 2010 National ANC sentinel survey for Anambra state, Nigeria [9].

\section{Results}

The crude HIV prevalence among 50 years and above in this study was $8.2 \%$ (361/4384) (Tables 1 and 2).

Table 1 shows that $92.3 \%$ of the population that attended HCT in the five years studied were 15 - 49 years of age while $4.8 \%$ and $2.9 \%$ were 50 - 59 years and 60 years of age and above respectively.

Table 2 shows 1) a seropositivity of 2.4 times higher 10.5\% (290/2749) in the 50 - 59 years of age compared to $4.3 \%(71 / 1635)$ in the 60 years of age and above population.

2) A higher HIV prevalence in females 8.8\% (179/2041) compared to males $7.8(182 / 2343)$.

3) The prevalence of HIV in the 15 - 49 years of age from the extrapolated data was $11.7 \%(6158 / 52,706)$ compared to $8.2 \%$ in 50 years of age and above.

4) No female 75 years and over were found to have HIV infection in our study $0 \%(0 / 62)$ while males in the same age group had a prevalence of $3.0 \%(4 / 134)$.

5) A higher HIV prevalence of $10.0 \%$ for males and females 15 - 49 years of age from the HCT data we extrapolated for the same 2010 compared to the $8.7 \%$ in the 2010 National ANC sentinel survey for Anambra state Nigeria (Federal Republic of Nigeria, 2010).

Table 1. The extrapolated data/population screened and the yearly uptake of HCT in Nnewi 2008 to 2012.

\begin{tabular}{ccccc}
\hline Years & Total screened & $15-49$ years & $50-59$ years & $60+$ \\
2008 & 15,060 & $13,958(92.7 \%)$ & $684(4.5 \%)$ & $418(2.8 \%)$ \\
2009 & 11,990 & $11,188(93.3 \%)$ & $93(4.1 \%)$ & $309(2.6 \%)$ \\
2010 & 11,023 & $10,054(91.2 \%)$ & $616(5.6 \%)$ & $253(3.2 \%)$ \\
2011 & 10,273 & $9587(93.3 \%)$ & $428(4.2 \%)$ & $2.5 \%)$ \\
2012 & 8744 & $7919(90.6 \%)$ & $528(6.0 \%)$ & $297(3.4 \%)$ \\
Total & $57,090(100 \%)$ & $52,706(92.3 \%)$ & $2749(4.8 \%)$ & $1635(2.9 \%)$ \\
\hline
\end{tabular}


Table 2. HIV prevalence (\%) by age and gender among adults 50 years and above in Nnewi, Nigeria.

\begin{tabular}{|c|c|c|c|c|c|c|c|c|c|c|}
\hline \multirow[b]{2}{*}{ Age (yrs) } & \multicolumn{2}{|c|}{2008} & \multicolumn{2}{|c|}{2009} & \multicolumn{2}{|c|}{2010} & \multicolumn{2}{|c|}{2011} & \multicolumn{2}{|c|}{2012} \\
\hline & Males & Females & Males & Females & Males & Females & Male & Females & Males & Females \\
\hline $50-54$ & $\begin{array}{c}26 / 252 \\
(10.3)\end{array}$ & $\begin{array}{c}26 / 184 \\
(14.1 \%)\end{array}$ & $\begin{array}{l}16 / 167 \\
(9.6 \%)\end{array}$ & $\begin{array}{c}15 / 124 \\
(12.2 \%)\end{array}$ & $\begin{array}{l}18 / 197 \\
(9.1 \%)\end{array}$ & $\begin{array}{c}26 / 216 \\
(12.0 \%)\end{array}$ & $\begin{array}{c}6 / 136 \\
(4.5 \%)\end{array}$ & $\begin{array}{l}10 / 142 \\
(7.0 \%)\end{array}$ & $\begin{array}{c}24 / 164 \\
(14.6 \%)\end{array}$ & $\begin{array}{c}31 / 190 \\
(16.3)\end{array}$ \\
\hline $55-59$ & $\begin{array}{l}13 / 133 \\
(9.8 \%)\end{array}$ & $\begin{array}{c}14 / 115 \\
(12.1 \%)\end{array}$ & $\begin{array}{l}10 / 106 \\
(9.4 \%)\end{array}$ & $\begin{array}{c}8 / 96 \\
(8.3 \%)\end{array}$ & $\begin{array}{l}6 / 109 \\
(5.5 \%)\end{array}$ & $\begin{array}{c}5 / 94 \\
(5.3 \%)\end{array}$ & $\begin{array}{c}4 / 67 \\
(5.9 \%)\end{array}$ & $\begin{array}{c}5 / 83 \\
(6.0 \%)\end{array}$ & $\begin{array}{c}18 / 108 \\
(16.7 \%)\end{array}$ & $\begin{array}{c}9 / 66 \\
(16.3 \%)\end{array}$ \\
\hline $60-64$ & $\begin{array}{c}5 / 99 \\
(5.0 \%)\end{array}$ & $\begin{array}{c}6 / 101 \\
(5.9 \%)\end{array}$ & $\begin{array}{l}5 / 76 \\
(5.6)\end{array}$ & $\begin{array}{c}3 / 68 \\
(4.4 \%)\end{array}$ & $\begin{array}{c}6 / 89 \\
(6.7 \%)\end{array}$ & $\begin{array}{c}5 / 94 \\
(5.3 \%)\end{array}$ & $\begin{array}{c}3 / 57 \\
(5.2 \%)\end{array}$ & $\begin{array}{c}4 / 53 \\
(7.5 \%)\end{array}$ & $\begin{array}{c}3 / 71 \\
(4.2 \%)\end{array}$ & $\begin{array}{c}4 / 75 \\
(5.3 \%)\end{array}$ \\
\hline $65-69$ & $\begin{array}{c}2 / 62 \\
(3.2 \%)\end{array}$ & $\begin{array}{c}2 / 36 \\
(5.6 \%)\end{array}$ & $\begin{array}{c}5 / 59 \\
(8.4 \%)\end{array}$ & $\begin{array}{c}2 / 47 \\
(4.2 \%)\end{array}$ & $\begin{array}{c}2 / 38 \\
(5.2 \%)\end{array}$ & $\begin{array}{c}2 / 30 \\
(6.7 \%)\end{array}$ & $\begin{array}{l}0 / 38 \\
(0 \%)\end{array}$ & $\begin{array}{c}1 / 29 \\
(3.4 \%)\end{array}$ & $\begin{array}{c}1 / 32 \\
(3.1 \%)\end{array}$ & $\begin{array}{l}0 / 39 \\
(0 \%)\end{array}$ \\
\hline $70-74$ & $\begin{array}{c}3 / 41 \\
(7.3 \%)\end{array}$ & $\begin{array}{l}0 / 24 \\
(0 \%)\end{array}$ & $\begin{array}{l}0 / 19 \\
(0 \%)\end{array}$ & $\begin{array}{l}0 / 20 \\
(0 \%)\end{array}$ & $\begin{array}{c}1 / 41 \\
(2.4 \%)\end{array}$ & $\begin{array}{l}0 / 18 \\
(0 \%)\end{array}$ & $\begin{array}{c}1 / 23 \\
(4.3 \%)\end{array}$ & $\begin{array}{c}1 / 25 \\
(4.0 \%)\end{array}$ & $\begin{array}{c}0 / 25 \\
(0 \%)\end{array}$ & $\begin{array}{l}0 / 10 \\
(0 \%)\end{array}$ \\
\hline $75+$ & $\begin{array}{c}3 / 47 \\
(6.3 \%)\end{array}$ & $\begin{array}{c}0 / 8 \\
(0 \%)\end{array}$ & $\begin{array}{c}0 / 13 \\
(0 \%)\end{array}$ & $\begin{array}{c}0 / 7 \\
(0 \%)\end{array}$ & $\begin{array}{l}0 / 30 \\
(0 \%)\end{array}$ & $\begin{array}{l}0 / 13 \\
(0 \%)\end{array}$ & $\begin{array}{l}0 / 15 \\
(0 \%)\end{array}$ & $\begin{array}{l}0 / 18 \\
(0 \%)\end{array}$ & $\begin{array}{c}1 / 29 \\
(3.4 \%)\end{array}$ & $\begin{array}{l}0 / 16 \\
(0 \%)\end{array}$ \\
\hline Total & $\begin{array}{l}52 / 634 \\
(8.2 \%)\end{array}$ & $\begin{array}{c}48 / 468 \\
(10.2 \%)\end{array}$ & $\begin{array}{l}36 / 440 \\
(8.1 \%)\end{array}$ & $\begin{array}{l}28 / 362 \\
(7.7 \%)\end{array}$ & $\begin{array}{l}33 / 504 \\
(6.9 \%)\end{array}$ & $\begin{array}{l}38 / 465 \\
(8.1 \%)\end{array}$ & $\begin{array}{l}14 / 336 \\
(4.1 \%)\end{array}$ & $\begin{array}{c}21 / 350 \\
(6 \%)\end{array}$ & $\begin{array}{c}47 / 429 \\
(10.9 \%)\end{array}$ & $\begin{array}{c}44 / 396 \\
(11.1 \%)\end{array}$ \\
\hline $50-59$ & $\begin{array}{c}39 / 385 \\
(10.1 \%)\end{array}$ & $\begin{array}{c}40 / 299 \\
(13.3 \%)\end{array}$ & $\begin{array}{l}26 / 273 \\
(9.5 \%)\end{array}$ & $\begin{array}{c}23 / 220 \\
(10.4 \%)\end{array}$ & $\begin{array}{l}24 / 306 \\
(7.8 \%)\end{array}$ & $\begin{array}{c}31 / 310 \\
(10.0 \%)\end{array}$ & $\begin{array}{l}10 / 203 \\
(4.9 \%)\end{array}$ & $\begin{array}{l}15 / 225 \\
(6.6 \%)\end{array}$ & $\begin{array}{c}42 / 272 \\
(15.4 \%)\end{array}$ & $\begin{array}{c}40 / 256 \\
(15.6 \%)\end{array}$ \\
\hline $60+$ & $\begin{array}{l}13 / 249 \\
(5.2 \%)\end{array}$ & $\begin{array}{c}8 / 169 \\
(4.7 \%)\end{array}$ & $\begin{array}{l}10 / 167 \\
(5.9 \%)\end{array}$ & $\begin{array}{l}5 / 142 \\
(3.5 \%)\end{array}$ & $\begin{array}{c}9 / 198 \\
(4.5 \%)\end{array}$ & $\begin{array}{c}7 / 155 \\
(4.5 \%)\end{array}$ & $\begin{array}{c}4 / 133 \\
(3.0 \%)\end{array}$ & $\begin{array}{c}6 / 125 \\
(4.8 \%)\end{array}$ & $\begin{array}{l}5 / 157 \\
(3.1 \%)\end{array}$ & $\begin{array}{c}4 / 140 \\
(2.8 \%)\end{array}$ \\
\hline
\end{tabular}

\section{Discussion}

To our knowledge, this study is the first to determine the prevalence of HIV among 50 years and above attending HIV Counseling Testing (HCT) in Nigeria. This study has found that uptake of HCT among males and females 50 years and above is low in Nnewi, Nigeria.

HIV infection has affected persons of all ages. Yet HIV prevalence among 50 years and above has largely been ignored in developing countries [6]. The crude HIV infection in our study was high (8.2\%). This high prevalence in the older adult may be due to late HIV testing. The majority of cases may not be acute infection, but rather chronic, long standing HIV infection. Besides, older adults may not use any barrier method to protect themselves from infection. Furthermore, older and affluent men may lure younger girls/boys into sex with their wealth which raises concern of increase HIV exposure risk in this age group (older adults) even though their prevalence may be relatively low.

The higher prevalence of HIV among females in our study could be attributed to the biology of their vagina, older adult women are at greater risk of HIV infection during intercourse due to age related reduced vaginal lubrication and thinning of the vaginal walls resulting from estrogen loss coupled with a decline in immune system [10] as this may cause tears in the vaginal area during sex, post menopausal women may not see the need for condom use because they are no longer at risk of pregnancy [11]. Routine HCT identified a large number of undiagnosed HIV infections [12].

Similarly, other pilot programmes have shown that more HIV infections can be identified by routine HCT than by testing based on risk assessment and clinical diagnosis [13]-[15]. HCT testing is free, besides, access to care and treatment in Nigeria has improved. The low uptake (7.7\%) of HCT among our participants (50 years and above) may be due to the fact that old people believe they are too old to be infected by HIV and other Sexually Transmitted infections (STIs) even those who engage in high - risk sexual activities, including unprotected sex with multiple partners and or/commercial sex workers and the misconception that older people are no longer sexually active. Most HIV prevention efforts largely target younger people, posters about HIV risk and prevention feature youthful faces, HIV positive pregnant women and HIV positive mothers breastfeeding their babies. Additionally, poor awareness of HIV risk factors (including safe sex practices) is a contributing factor. This population also lack up-to-date information about disease prevention and transmission [12] [16]. Many mature adults in Nnewi and environs are poor and reside in very remote villages far from HCT center and may not have 
the resources to seek HCT and medical attention. The higher prevalence among age group 50 - 59 (10.5\%) compared to (4.3\%) among 60 years and older could be associated with the increased sexual activity among this group as sexual activity decreases with advancing age.

There are more males 53.4\% (2343/4384) compared to females $46.6 \%$ (2041/4384) in the study population. Males' preponderance in our study can be attributed to underutilization of HCT services by females. Additionally, females in our setting seem to hide their actual age because of some marriage related issues.

The prevalence of 15 - 49 years we extrapolated from 2010 HCT data was higher (10.0\%) than the 8.7\% in the same age group for the 2010 national ANC sentinel survey for Anambra state, Nigeria (Federal Republic of Nigeria, 2010). This could be attributed to the fact that the national ANC sentinel survey recruits only pregnant women while we extrapolated the data of both sexes within 15 - 49 years in our study.

This study has confirmed that HIV infection affects the younger population (15 - 49 years of age) $11.7 \%$ (6158/52,706) more than the middle aged (10.5\%) and older population 4.3\% (361/4384). This result has also shown that the virus is not a respecter of any age The trends in HIV infection in age showed a decreasing prevalence as the age advances in the five years studied.

\subsection{Limitation}

We had no access to the population figure of middle aged (50 - 59 years of age) and geriatrics (60 years and above) for Nnewi, Nigeria to help us calculate the percentage of 50+ who attended HCT in our study.

The likelihood that most females hid their true age in our setting may have affected the population of women studied and

Participants in the window period (those with undetected HIV antibodies).

\subsection{Strengths}

The HIV prevalence rates observed and the sample size studied seem to be a better data representative for Nnewi and environs compared to the prevalence and sample size and population studied in the 2010 ANC sentinel survey for Anambra State.

\subsection{Recommendations}

Clinicians should make HCT testing a core component of public and private hospitals services for all patients/ clients assessing medical and surgical treatments in Nigeria and in Sub-Saharan Africa (SSA) where the HIV burden is high. A mobile HCT (house to house testing) will help to tackle the low levels of HIV testing among older people that was observed in our study. Older peer educators should be used as counselors in other to improve their access to HCT. Finally, HIV screening should be considered in sexually active older persons, even if they report being monogamous. There is a critical gap in the knowledge on HIV in mature adults that ,if not properly addressed may hinder UNAIDS's vision of zero discrimination, zero new HIV infection and zero AIDS-related deaths through universal access to effective HIV prevention, treatment, care and support. We therefore emphasize the urgent need to focus on mature adults in the HIV prevention programmes.

\section{Conclusion}

Our findings show that offering HCT routinely is feasible and may increase linkage to HIV care and treatment for many individuals with HIV infections. Routine HCT should be an integral component of any expansion in HIV prevention, care and treatment services in Africa and other settings where the prevalence of HIV is high. House to house HIV testing will improve uptake of testing among older population in developing countries. Interventions aimed at improving policies and practices that will increase HIV screening within the older population which must be encouraged. Efforts should be made to increase knowledge about HIV and the importance of HIV screening among individuals aged 50 years and above.

\section{Declaration of Interests}

There is no conflict of interests in this study. 


\section{Authors' Contributions}

SOK, FR and ON conceived the study. SOK, EPU, ON, FR, CGO, AIO, AAE participated in the study design. SOK, BOO, AAE, AIO, CGO, NSA, EPU drafted the article. SOK and CGO performed the statistical analysis. EPU provided critical review of the article. All the participants read and approved the final manuscript.

\section{Acknowledgements}

The authors would like to thank the Institute of Human Virology-Nigeria with fund from the US President's Emergency Plan For AIDS Relief (PEPFAR) and the Federal Ministry of Health (FMOH) Nigeria for their support through the provision of HIV rapid test kits. All the counselors and staff of Nnamdi Azikiwe University Teaching Hospital working in the HCT unit and all the participants involved in this study for their contributions to this study.

\section{References}

[1] Saucier, J.F. (1972) Correlates of the Post-Partum Taboo: A Cross-Cultural Study. Current Anthropology, 13, $238-277$. http://dx.doi.org/10.1086/201273

[2] Caldwell, J.C., Caldwell, P. and Quiggin, P. (1989) The Social Context of AIDS in Sub-Saharan Africa. Population and Development Review, 15, 185-234. http://dx.doi.org/10.2307/1973703

[3] United Nations (2007) Department of Economic and Social Affairs: World Population Ageing 2007. United Nations, New York.

[4] Baggily, R. (2001) The Impact of Voluntary Counselling and Testing: A Global Review of the Benefits and Challenges. UNAIDS, Geneva, UNAIDS/01.32E.

[5] Gresenguet, G., Sehonou, J., Bassirou, B., de Longo, J.D., Malkin, J.E., Brogan, T., et al. (2002) Voluntary HIV Counselling and Testing: Experience among the Sexually Active Population in Bangui, Central African Republic. Journal of Acquired Immune Deficiency Syndromes, 31, 106-114.

[6] Negin, J., Bennett, R.C., Lelerai, E., Amor, Y.B. and Pronyk, P. (2011) HIV Attitude, Awareness and Testing among Older Adults in Africa. AIDS Behavior, 16, 63-68.

[7] Negin, J. and Cumming, R.G. (2010) HIV Infection in Older Adults in Sub-Saharan Africa: Extrapolating Prevalence from Existing Data. Bulletin of the World Health Organization, 88, 847-853. http://dx.doi.org/10.2471/BLT.10.076349

[8] Ory, M.G. and Mack, K.A. (1998) Middle-Aged and Older People with AIDS. Research on Aging, 20, 653-664.

[9] Federal Republic of Nigeria (2012) HIV Prevalence (\%) by States. (HSS 2010) Global AIDS Response Progress Report (GARPR) 2012.

[10] Schatz, E. and Ogunmefun, C. (2007) Caring and Contributing: The Role of Older Women in Rural South African Multi-Generational Households in the HIV/AIDS Era. World Development, 35, 1390-1403. http://dx.doi.org/10.1016/j.worlddev.2007.04.004

[11] Key, S. and DeNoon, D. (1998) AIDS Increasing among Elderly, Particularly Women: AIDS Weekly Plus. Retrieved from EBSCO Publishing 2003.

[12] Walensky, R.P., Losina, E., Steger-Craven, K.A. and Freedberg, K.A. (2002) Identifying Undiagnosed Human Immunodeficiency Virus: The Yield of Routine, Voluntary Inpatient Testing. Archives of Internal Medicine, 162, 887-892. http://dx.doi.org/10.1001/archinte.162.8.887

[13] Centers for Disease Control and Prevention (2001) Routinely Recommended HIV 22. Testing at an Urban Urgent-Care Clinic, Atlanta, Georgia, 2000. Morbidity and Mortality Weekly Report, 50, 538-541.

[14] Centers for Disease Control and Prevention (2002) Voluntary HIV Testing as Part of Routine Medical Care-Massachusetts, 2002. Morbidity and Mortality Weekly Report, 53, 523-526.

[15] Creek, T., Ntumy, R., Seipone, K., Smith, M., Mogodi, M., Smit, M., et al. (2007) Successful Introduction of Routine Opt-Out HIV Testing in Antenatal Care in Botswana. Journal of Acquired Immune Deficiency Syndromes, 45, 102-107. http://dx.doi.org/10.1097/QAI.0b013e318047df88

[16] Beckwith, C.G., Flanigan, T.P., del Rio, C., Simmons, E., Wing, E.J. and Carpenter, C.C. (2005) It Is Time to Implement Routine, Not Risk-Based HIV Testing. Clinical Infectious Diseases, 40, 1037-1040. http://dx.doi.org/10.1086/428620 